\title{
Development of monitoring system for marine air compressor unit based on PLC
}

\author{
Baocheng $\mathrm{Lu}^{\mathrm{a}}$, Zhaoqiang $\mathrm{Li}^{\mathrm{b}}$ \\ Binzhou Polytechnic, Binzhou 256600, China \\ a176816963@qq.com, b474637466@qq.com
}

Keywords: PLC, PC Machines, Air Compressor Monitoring System.

\begin{abstract}
PLC technology and PC machines is combined together in order to design a visual remote operation and monitoring system which based on the configuration software. PLC technology and PC machines communicate via MPI and PROFIBUS-DP to make remote operations and monitoring fast and reliable. This system describes the composition and function of marine air compressor operation mode, programming software and PC monitor screen. The feasibility and effectiveness of the system is verified through the use of the ship. Therefore, the experimental results show the feasibility and effectiveness of the system. This system prove that it can improve control function of monitoring system.
\end{abstract}

\section{Introduction}

Marine air compressor is one of the most important auxiliary equipment in the main propulsion power plant. It is mainly used to store the compressed air to the air bottle. Compressed air is supplied to the ship's main engine, generator and other equipment. The ship air compressor is equipped with 3 units, they are 2 main air compressor and 1 emergency air compressor, and we usually refer to them as marine air compressor units. Each compressor is related to electromagnetic valve, temperature, pressure, liquid level and other parameters, Traditional management needs manual timing to check and adjust to the machine, and it consumes a lot of manpower and the maintenance management lags.

Aiming at the present situation, we design a monitoring system based on PLC which can exchange information and instructions, the control system adopts PLC control to improve reliability, the PC monitors the operation parameters and the alarm, and then changes the parameters directly on the PC. This system can effectively improve the reliability, rapidity and safety of air compressor unit monitoring.

\section{Control Content}

A ship equipped with 3 air compressors and 3 air bottles. Two wp400-100 main air compressor, air volume $280 \mathrm{~m}^{3} / \mathrm{h}$, one wp400-100 emergency compressor, air volume $144 \mathrm{~m}^{3} / \mathrm{h}, 2$ main air bottles, maximum pressure 3.0 Mpa, 1 emergency air bottle, maximum pressure 3.0 Mathew air compressor is a two-stage water-cooling single row type. This design mainly monitors the operation mode of air compressor unit and the operation parameters of compressor.

\subsection{Operation Mode}

PLC default air compressor operation mode, the operating level of manual mode is preferred for automatic mode, the operating level of the automatic mode should be preferred in remote control mode. After maintenance or other special circumstances, we choose to use manual mode.

\subsubsection{Automatic Operation}

The pressure signal collected by the pressure sensor is converted to PLC, After PLC analysis and judgment, the PLC issued instructions to control the start or stop of the air compressor. When the pressure reaches the upper limit of 3.0Mpa, the air compressor stops, when the pressure is at a lower limit of $2.4 \mathrm{Mpa}$ or at $2.5 \mathrm{Mpa}$, the air compressor starts. 
In order to avoid the use of the same air compressor for long time, the engineer will adjust the order of the main air compressor according to the operation time and the operation condition.

\subsubsection{Manual Operation}

According to the air pressure value, when the pressure drops to $2.4 \mathrm{Mpa}$, the engineer starts the 1 air compressor, when the pressure rises to $3.0 \mathrm{Mpa}$, the engineer stops the compressor. If the main engine starts to stop frequently, a lot of compressed air is required, and the engineer can manually start two air compressors at the same time, ensuring that the air needs are met. It is important to note that when the system is running manually, when the pressure exceeds $3.0 \mathrm{Mpa}$, the air compressor is not automatically stopped.

\subsubsection{Remote Control}

Marine engine room equipment can be remotely controlled, remote control panel is installed in the engine room control room. For the convenience of the Engineer in the centralized control room air compressor, in the control room console set remote control panel PC and air compressor, can realize remote start stop and parameter monitoring.

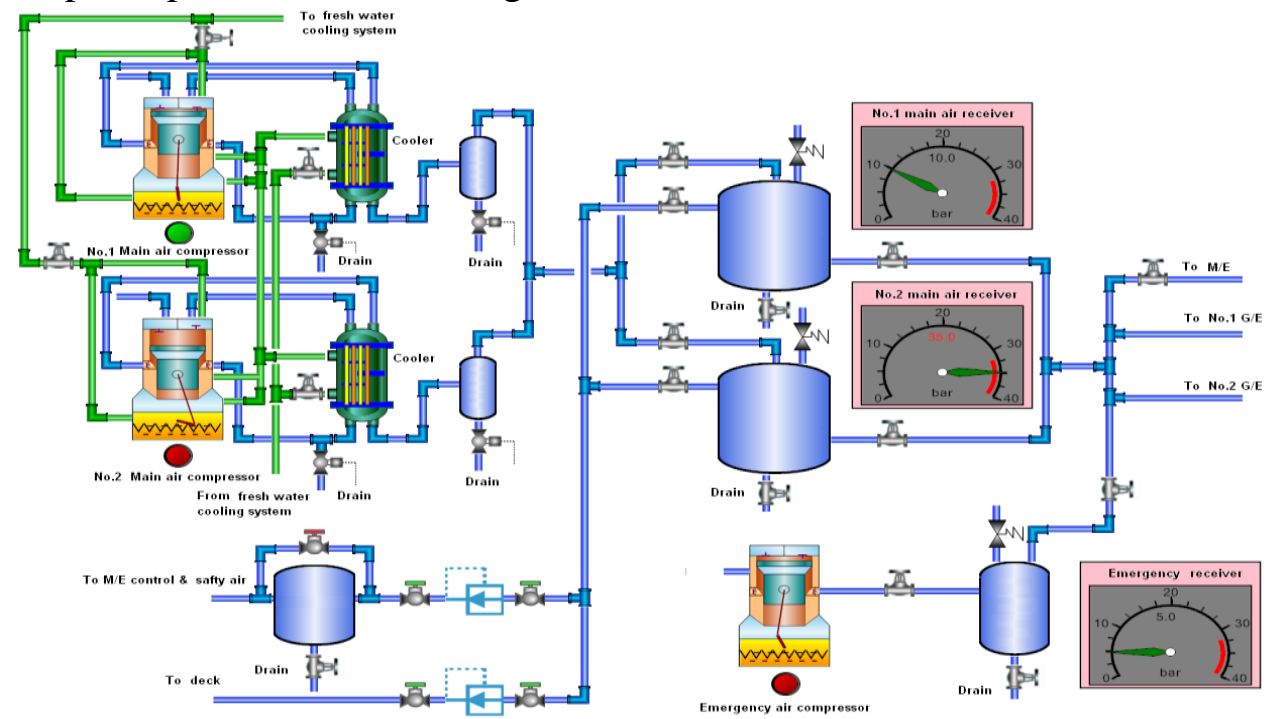

Fig. 1 Ship compressed air system diagram

\subsection{Control Parameters}

In order to ensure the normal air supply of air compressor unit, it is necessary to monitor the pressure, temperature and solenoid valve parameters.

When the pressure is lower than the set pressure value, the cooling water of air compressor and the electromagnetic valve is opened, start cooling air compressor, PLC gives an instruction soft starter to start the air compressor, air compressor delay after first and two unloading solenoid valve closed unloading, air compressor cylinders to air, when the pressure reaches the set value, the air compressor stops.

The first and two stage of the air compressor unloaded the solenoid valve to open. Cooling water inlet and outlet solenoid valve delay closing. In the whole process of operation, the PLC monitors the pressure and temperature of the oil, the pressure and temperature of the cooling water and the pressure of the air bottle. The PLC automatically selects the main air compressor according to the engineer's instruction.

\section{Hardware Design}

The hardware includes the master PC, SIEMENS SL300PLC, ET200M from the station, pressure sensor, and temperature sensor and solenoid valve.

$\mathrm{PC}$ is responsible for the configuration software which can view the system status and parameters, it can start, and switch air compressor shutdown, and adjust the parameters, it can alarm signal storage and alarm simulation, and install a printer which can print real-time alarm program. The PC is installed 
in an ordinary desktop computer, installed in the cabin room, and can be extended in the captain's room.

PLC uses SIEMENS S7-314, S7-300 series control system integrated automation of the most dynamic areas, combined with the formation of ET200M security technology more distributed, and can use the world standard high efficiency STEP7 configuration and programming based on Integrated Diagnosis Based on the powerful with availability, higher running fast, reduce the cost of the project, to reduce operating costs, with MPI and PROFIBUS-DP communication interface.

ET200S from the station to receive the remote sensor signal acquisition, there are integrated CUP interface module, the local control of air compressors can be achieved through PROFIBUS communication module expansion, it has a wealth of diagnostic functions.

The temperature sensor uses PT100 temperature sensor, which is used to detect the temperature of cooling water and oil.

The pressure sensor is SIEMENS QBE3000-D10 which is used to measure the pressure of compressed air, lubricating oil and cooling water.

Solenoid valve OPT-A OPT-B is used to control the air compressor unloading, solenoid valve 2W160-15 is used to control the cooling water inlet and outlet air compressor.

The air compressor can be controlled by remote control of PC software and can also be controlled in the engine room control room, and can be controlled by the machine.

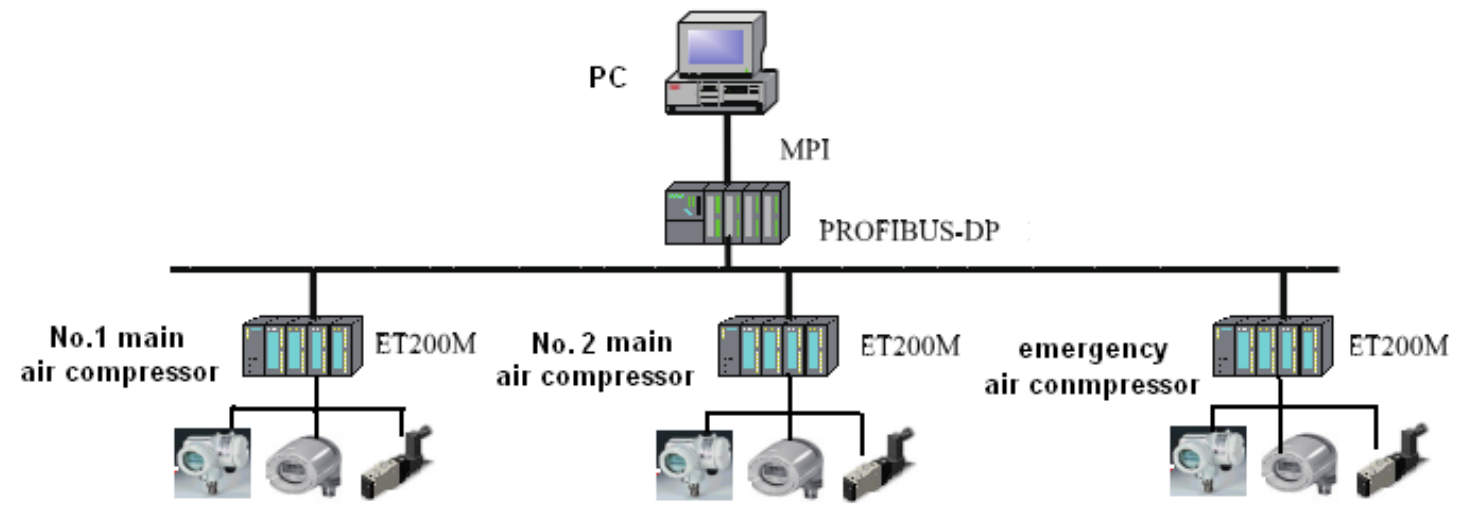

Fig. 2 monitoring system structure diagram

\section{Software Design}

\subsection{Programming Software}

PLC uses SIEMENS's STEP7 V5.5 programming software, It is the SIEMENS S7-314 programming and maintenance software, through the STEP7 V5.5 programming software, the user can program the realization of air compressor start, stop, unload, fault alarm and remote monitoring functions, It can disconnect the hardware testing and debugging, online diagnosis of PLC hardware state, control PLC, control the state of the I/O channel to complete the analog and switch input and output, the sensor collects the field data and transfers the data to PLC, PLC accepts a control signal from the PC, and control equipment. Its programming includes automatic control module, manual control module, analog processing module, communication module and alarm module.

\subsection{Monitoring Interface}

Made in Beijing, Kunlun state automation software technology Co., Ltd. Kunlun state MCGSE configuration software is installed on the PC machine, It can provide a simple and flexible operation interface, it can make full use of multi-tasking and priority operation function, practical. It is rich in vivid multimedia images, a variety of alarm functions.

According to the characteristics of the system and the requirements of the operator, the software can output the real-time curve and history curve of the air bottle pressure, It can detect the temperature and pressure data of air compressor set, It can be based on the requirements of users to save and access to historical data, in accordance with the requirements of users to print the project report. 
The PC machine is composed of 5 monitoring pictures of the air compressor unit control screen, the air compressor running dynamic picture, the monitoring system parameter picture, the system alarm display screen and the system parameter adjustment screen. The air compressor unit control screen is provided with 3 operation modes of the air compressor, a control switch and a priority start sequence control switch in the automatic mode. Air compressor running dynamic picture set 3 air compressor movement parts simulation diagram, air output graphics, the electromagnetic valve, the valve switch state display. The parameters of the monitoring system can display the operating parameters of each air compressor and the parameters of the air bottle. System alarm display screen can display the alarm information in real time, you can also access the historical alarm information. If you need to enter the system parameters to adjust the screen, the operator needs to have administrator password to enter the operation of the system parameters.

Each interface is set at the top of the interface button and return button, you can enter and exit an interface at any time.

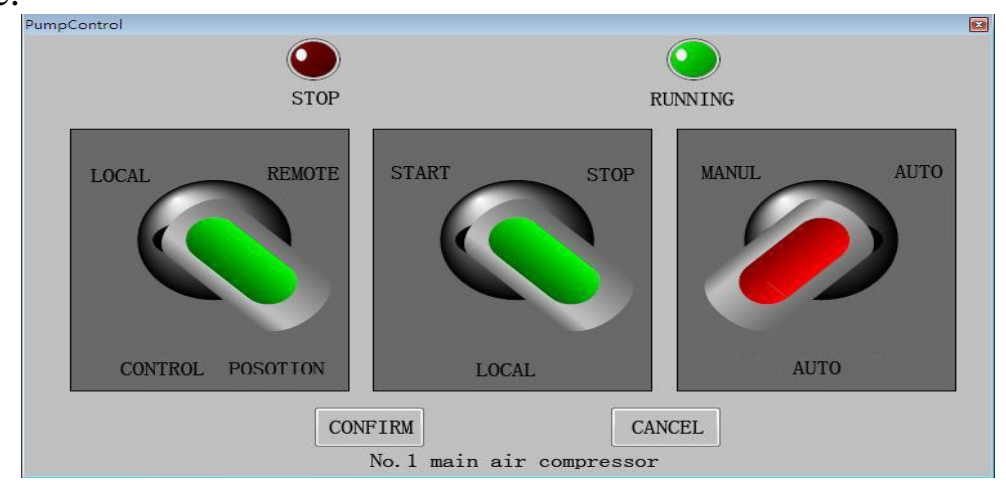

Fig. 3 No.1 main air compressor control screen

The PC system software sets the administrative authority, the administrative authority is divided into two levels, and the level 1 operator can view the interface at any time, but can't change any data. Level 2 administrators can use password authorization to enter the system to change the system parameters.

\section{Conclusion}

The system has been tested on site, and the ship is in use, after 2 years of use feedback, running conditions show, the PLC control system runs well, the man-machine interface is easy to operate, the work is reliable, the debugging is simple, the system communication is smooth, the state information is clear and comprehensive, the program can reliably implement the air pressure unit's start-stop program, this system greatly facilitates the management of equipment. In the future, we should pay attention to the cost saving and hardware installation and wiring Work.

\section{References}

[1]. E.B. Priyanka, C. Maheswari, B. Meenakshipriya. PARAMETER MONITORING AND CONTROL DURING PETROL TRANSPORTATION USING PLC BASED PID CONTROLLER [J]. Journal of Applied Research and Technology. 2016.

[2]. Jiazhen Zhang, Pengfei Wei, Ke Gao. Application of multiple air compressor control technology in offshore oil platform [J]. Petroleum and chemical equipment. 2016.

[3]. Li Liu. Design of monitoring and control system for PLC liquid mixing device based on configuration software [J]. Automation technology and Application. 2015.

[4]. Busyairah Syd Ali. System specifications for developing an Automatic Dependent Surveillance-Broadcast (ADS-B) monitoring system [J]. International Journal of Critical Infrastructure Protection. 2016.

[5]. Deepam Goyal,B.S. Pabla. Development of Non-Contact Structural Health Monitoring System for Machine Tools [J]. Journal of Applied Research and Technology. 2016. 